\title{
SUPLEMENTAÇÃO DE VITAMINA D NA PREVENÇÃO DE INFEÇÕES AGUDAS DO TRATO RESPIRATÓRIO: REVISÃO SISTEMÁTICA E META-ANÁLISE DE DADOS INDIVIDUAIS \\ VITAMIN D SUPPLEMENTATION TO PREVENT ACUTE RESPIRATORYTRACT INFECTIONS: SYSTEMATIC REVIEW AND META-ANALYSIS OF INDIVIDUAL PARTICIPANT DATA
}

Martineau AR, Jolliffe DA, Hooper RL, Greenberg L, Aloia JF, Bergman P, et al. Vitamin D supplementation to prevent acute respiratory tract infections: systematic review and meta-analysis of individual participant data. BMJ. 2017;356:i6583. doi: 10.1136/bmj.i6583

MeSH Terms: Vitamin D; Respiratory tract infections

\section{Introdução}

Estudos observacionais têm demonstrado uma associação entre baixas concentrações séricas de 25-hidroxivitamina D (o principal metabolito da vitamina D em circulação) e suscetibilidade para infeções agudas do trato respiratório.

$\mathrm{O}$ mecanismo pelo qual a vitamina $\mathrm{D}$ diminui o risco destas infeções parece estar relacionado com a capacidade deste metabolito em induzir a expressão de peptídeos em resposta a estímulos víricos e bacterianos.

Previamente a esta meta-análise, tinham sido realizadas cinco meta-análises com análise agrupada de dados obtidos a partir de quinze ensaios clínicos, sendo que apenas duas delas mostraram efeitos benéficos estatisticamente significativos. Estas meta-análises relataram uma heterogeneidade estatisticamente significativa dos dados obtidos nos ensaios, como resultado da variação das características dos participantes e das doses de vitamina D utilizadas.

Os autores realizaram uma meta-análise com análise individual de dados obtidos de 25 ensaios clínicos randomizados controlados, existentes até dezembro de 2015 , sobre a suplementação de vitamina D na prevenção de infeções agudas do trato respiratório, de forma a confirmar este efeito e a identificar os fatores modificadores deste efeito.

\section{Métodos}

Procederam a uma pesquisa bibliográfica nas bases de dados de medicina baseada na evidência de publicações editadas até dezembro de 2015.

Foram incluídos ensaios clínicos randomizados, controlados e duplamente cegos com a suplementação de vitamina D3. Só foram incluídos os ensaios aprovados por comissão de ética e com dados de incidência de infeção aguda do trato respiratório, colhidos de forma prospetiva e pré-especificados como outcome de eficácia.
O outcome primário foi a incidência de infeção aguda do trato respiratório, incluindo eventos classificados como infeção do trato respiratório superior, infeção do trato respiratório inferior e infeção do trato respiratório de localização indeterminada.

Os outcomes secundários foram: a incidência de infeções do trato respiratório superior e inferior, analisados separadamente; a incidência de admissão no serviço de urgência ou internamento hospitalar, ou ambos; o tratamento de infeção aguda do trato respiratório com antibioterapia; o absentismo escolar ou laboral por infeção aguda do trato respiratório; a incidência e natureza de eventos adversos graves; a incidência de potenciais reações adversas à vitamina $\mathrm{D}$, nomeadamente hipercalcemia e litíase renal; e a mortalidade relacionada com infeção aguda do trato respiratório e por todas as causas.

\section{Resultados}

Foram selecionados 25 ensaios clínicos randomizados e controlados, envolvendo um total de 11.321 participantes, com idades compreendidas entre os 0 e os 95 anos. Procedeu-se à análise de dados individuais em 10.933 participantes (96,6\%). A duração dos estudos variou entre sete semanas e 18 meses.

A concentração média basal de 25-hidroxivitamina $\mathrm{D}$ variou entre 18,9 a $88,9 \mathrm{nmol} / \mathrm{L}$. Foi administrada vitamina D3 oral no grupo de intervenção, na forma de bólus mensais a trimestrais em sete estudos; em doses semanais em três estudos; em dose diária em 12 estudos; e em terapêutica combinada de bólus e doses diárias em três estudos.

A incidência de infeção aguda do trato respiratório foi o outcome primário ou coprimário em 14 estudos e o outcome secundário em 11 estudos.

A suplementação de vitamina D reduziu o risco em $12 \%$ de infeção aguda do trato respiratório em todos os participantes (OR ajustado 0,88, IC95\%, 0,81-0,96; 
$p<0,001)$. A análise dos subgrupos mostrou benefícios nos que receberam vitamina $\mathrm{D}$ de forma diária ou semanal, sem bólus adicionais (OR ajustado 0,81, $0,72-0,91$ ), mas não naqueles que receberam um ou mais bólus (OR ajustado 0,97, 0,86-1,10; $p=0,05$ ). Nos que receberam vitamina $\mathrm{D}$ de forma diária ou semanal, os benefícios foram superiores nos que tinham uma concentração basal de 25-hidroxivitamina D $<25$ $\mathrm{nmol} / \mathrm{L}$ (OR ajustado 0,30, 0,17-0,53), em comparação com os que apresentavam uma concentração basal $\geq 25$ $\mathrm{nmol} / \mathrm{L}$ (OR ajustado 0,75, 0,60-0,95; $p=0,006$ ).

Os autores não encontraram um efeito benéfico estatisticamente significativo da suplementação de vitamina D nas idas ao serviço de urgência ou internamento hospitalar, duração de antibioterapia ou absentismo escolar ou laboral devido a infeção aguda do trato respiratório. Esta suplementação também não está associada a risco de eventos adversos por qualquer causa (OR ajustado $0,98,0,80-1,20$ ) ou morte por qualquer causa (OR ajustado 1,39, 0,85-2,27).

\section{Discussão}

A suplementação de vitamina D reduziu o risco de desenvolver pelo menos uma infeção aguda do trato respiratório. A análise dos subgrupos mostrou que a suplementação diária ou semanal, sem a adição de bólus, era benéfica na prevenção de infeções agudas do trato respiratório. Esse benefício foi superior nos que tinham uma concentração basal mais baixa de vitamina
D, embora também com benefício nos participantes com concentração superior de vitamina $\mathrm{D}$.

A concentração basal de vitamina $\mathrm{D}$ e a dose de suplementação são apontadas como fatores responsáveis, pelo menos em parte, pela heterogeneidade verificada nos ensaios prévios a esta meta-análise.

Uma hipótese para a ineficácia dos bólus de vitamina D na prevenção da infeção aguda do trato respiratório está relacionada com as flutuações na concentração sérica de 25-hidroxivitamina $\mathrm{D}$, após a administração em bólus. A elevada concentração sérica que se verifica após o bólus pode levar a uma desregulação das enzimas responsáveis pela síntese e degradação do metabolito ativo da vitamina $D, 1,25$ - dihidroxivitamina $\mathrm{D}$, o que resulta na sua menor concentração nos tecidos extra renais.

A maior eficácia da suplementação de vitamina $D$ nos participantes com menor concentração basal desta vitamina é facilmente explicável pelo princípio de que, quanto maior a deficiência de um micronutriente, maior é a resposta à sua suplementação.

\section{Conclusões}

Os autores concluem que a prevenção da infeção aguda do trato respiratório constitui uma nova indicação para a suplementação de vitamina D.

Os resultados desta meta-análise poderão ter impacto na implementação de medidas de saúde pública, como a suplementação alimentar com vitamina D, principalmente nos locais de maior carência.

\section{Comentário}

Nos últimos anos tem havido um interesse crescente sobre os efeitos da vitamina D na saúde, com a publicação de um elevado número de estudos.

Estudos observacionais têm estabelecido correlações entre baixos níveis séricos de 25-hidroxivitamina D3 e um conjunto de doenças crónicas, como doença cardiovascular, neoplasias, diabetes, fraturas e depressão, pelo que se tem decretado que a hipovitaminose D é «uma pandemia», necessitando de tratamento. ${ }^{1}$

$\mathrm{O}$ facto de a vitamina $\mathrm{D}$, entre outros efeitos, estar associada à inibição de citocinas inflamatórias envolvidas durante a infeção pelos vírus influenza tem também despertado o interesse para um possível papel desta vitamina na prevenção e redução de infeções agudas do trato respiratório. ${ }^{2}$

Sendo estas infeções uma importante causa de absentismo escolar e laboral, hospitalização e mortalidade, ${ }^{2-3}$ a confirmação desta associação poderá ter um importante impacto em termos de saúde pública.

No entanto, e apesar de já terem sido realizados vários ensaios clínicos nesta área, os resultados sobre o papel da vitamina D nestas infeções são discordantes, o que poderá ser explicado pela elevada heterogeneidade destes ensaios: diferem na população em estudo (saudável/com comorbilidades), locali- 
zação geográfica (norte/sul), nível basal e dose de vitamina D, esquema de suplementação (semanal/bólus) e duração do estudo. Todos estes aspetos podem ter impacto no outcome do respetivo estudo.

A análise agrupada de dados, utilizada nestes estudos, não permite a identificação de fatores potencialmente modificadores a nível individual como, por exemplo, o nível basal de vitamina D. Pelo contrário, na meta-análise em estudo foi feita uma análise de dados a nível individual, sendo os resultados consistentes com a hipótese de que o nível basal de vitamina D e o esquema de suplementação são fatores independentes que modificam o efeito da suplementação da vitamina $\mathrm{D}$, embora outros fatores não possam ser excluídos.

Os autores verificaram uma redução em $12 \%$ no risco de infeção do trato respiratório associado à suplementação com vitamina D e um NTT de 33 (é necessária a suplementação com vitamina $\mathrm{D}$ em 33 pessoas, de forma a prevenir uma infeção do trato respiratório).

Segundo os autores, estes resultados contribuem para uma evidência adicional da suplementação de vitamina D como uma medida eficaz, segura e acessível na prevenção de infeções agudas do trato respiratório.

No entanto, algumas particularidades verificadas nesta meta-análise deverão levar a uma interpretação cautelosa dos resultados.

Um dos aspetos a salientar é a variabilidade das características da população estudada, com a inclusão de participantes originários de quinze países e quatro continentes diferentes. Tal facto pode afetar a concentração de vitamina $\mathrm{D}$, condicionada pela exposição solar associada à latitude, à diferente pigmentação cutânea e ao diferente estado nutricional.

Tendo em conta que $60 \%$ dos participantes tinham idade inferior a dezasseis anos, a extrapolação dos re- sultados obtidos para a população adulta pode ser algo questionável.

Salienta-se ainda o facto de a incidência de infeção aguda do trato respiratório ter sido o outcome primário ou coprimário em apenas 14 dos 25 estudos incluídos nesta meta-análise.

A acrescentar ainda o facto de não ter sido encontrado um efeito benéfico estatisticamente significativo da suplementação de vitamina D nas idas ao serviço de urgência ou internamento hospitalar, duração de antibioterapia ou absentismo escolar ou laboral devido a infeção aguda do trato respiratório.

A redução em $2 \%$ no risco absoluto de infeção do trato respiratório encontrada nesta meta-análise poderá não ser motivo suficiente para a implementação da suplementação com vitamina $D$ na população em geral.

Estes resultados deverão, assim, constituir um ponto de partida importante para o desenvolvimento de mais ensaios clínicos randomizados nesta área, com metodologia homogénea e amostras mais relevantes, antes de se concluir pela suplementação generalizada com vitamina D como medida preventiva de infeções agudas do trato respiratório.

Sophie Sousa USF Oceanos, Unidade Local de Saúde de Matosinhos

\section{REFERÊNCIAS BIBLIOGRÁFICAS}

1. Nair R, Maseeh A. Vitamin D: the 'sunshine' vitamin. J Pharmacol Pharmacother. 2012;3(2):118-26.

2. Vuichard Gysin D, Dao D, Gysin CM, Lytvyn L, Loeb M. Effect of vitamin D3 supplementation on respiratory tract infections in healthy individuals: a systematic review and meta-analysis of randomized controlled trials. PLoS One. 2016;11(9):e0162996.

3. Zittermann A, Pilz S, Hoffmann H, MärzW.Vitamin D and airway infections: a European perspective. Eur J Med Res. 2016;21:14.

\section{CONFLITOS DE INTERESSE}

A autora declara não possuir quaisquer conflitos de interesse. 